\title{
The Management of Logistics Finance Risk Based on the Platform of Internet of
}

\section{Things}

\author{
Boyu Su* \\ School of Management Engineering, Zhengzhou University, Zhengzhou, China
}

Keywords: financial company, management model design

\begin{abstract}
In recent years, logistics finance has improved considerably. The development of logistics finance is a pressing need of three parties including bank, logistics enterprise and lending enterprise. But at the same time, in order to carry out logistics finance business, providers must be exposed to various risks. It is necessary to analyze these risks correctly and control effectively, only then, the business can run smoothly, and a win-win situation is created (Yinlun Liu, Wangyang Han,2015). This paper, based on the research experience of international and domestic experts, focuses on the application of Internet of Things technology in risk prevention and control.
\end{abstract}

\section{INTRODUCTION}

Logistics Finance based on logistics industry, it refers to operation and development financial products and take on board, hoping to achieve effectively regulate and organize logistics in the process of monetary liquidity. It includes loans, mortgages, leases, investments, trusts, deposits, discounts, insurance, securities trading, etc., occurring in the logistics process. There are three main parts in Logistics Finance: customers, logistics enterprises and financial institutions, customers are funding requirements and require financing. The financial institutions and the logistics enterprises cooperate to provide funds for the financing enterprises. For three party entities, carrying out the logistics finance business is the common need of the three. The development of the logistics finance industry can ease the financing difficulties of SMEs in China, regulate the flow of money and reduce the waste of social resources (Juan Li,2007).

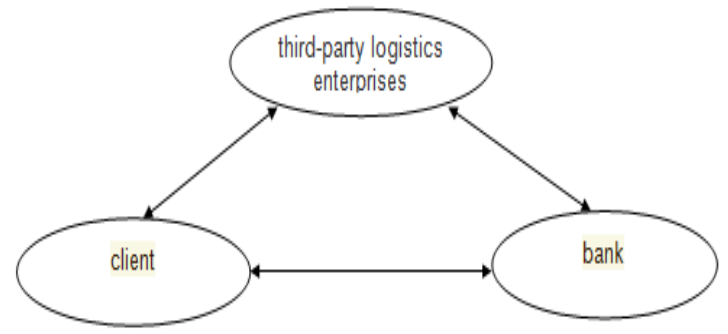

Fig 1 Logistics finance operation mode diagram

Although the development of logistics finance business can achieve win-win situation for all participants: financing enterprises, banks and third party logistics enterprises, but at the same time, the providers of logistics finance inevitably may face many risks. The correct analysis, effective management and prevention of these risks can ensure the smooth and efficient development of the logistics business. At present, the main measure of logistics financial risk management in our country is to select appropriate pledge, strengthen the credit management of financing enterprises, clear the terms of the contract, and clearly define the respective rights and responsibilities of the three parties. To a certain extent, these management measures can reduce the probability of all kinds of risk situations, however, the above risk management measures can not meet the needs of high-speed development of logistics finance. In many ways, there are certain limitations.

Nowadays, the scale of logistics finance in our country is expanding day by day, only by virtue of a company's power to investigate the pledge of the market value and the quality of the goods, the credit condition of financing enterprises, formulate the pledge protection measures and provides personalized, refine business contract on every obligation and power is very unrealistic. The three logistics financial parties collect information individually, make information record unilaterally, they can not guarantee the safety of information, timeliness and reliability becase of timely information feedback and information sharing,so they prone to information distortion and asymmetric information(Zhili Jia,2012).

\section{THE MANAGEMENT OF LOGISTICS FINANCIAL RISK USING INTERNET OF THINGS}

In 1999, the concept of the Internet of things was first proposed(IOT), it's seen as an extension of Internet applications. With the development of recent years, the Internet of things has become an indispensable part of the new era of information technology. It has been widely used in warehousing, logistics, intelligent transportation, industrial and agricultural monitoring, environmental monitoring, urban management and other fields. The Internet of things relies on technologies such as RFID, sensor technology, GPS technology, and wireless data network communications to connect things to the Internet and build a world that tightly integrated whole of things. In the Internet of things, the information is high-speed transmission and feedback, and support the whole network sharing, though a series of advanced technology to realize Identification, location, tracking, monitoring, It can also contribute to the enterprise management refinement, visualization and transparency (Junjing Yuan,Qi Tang,2014). 
The Internet of things has received extensive attention and rapid development in recent years, and the Internet of things technology has been applied to various fields and achieved the desired results. Using the Internet of things to carry out risk supervision of logistics finance needs the extensive participation of government departments and enterprises to reach a certain scale, a large amount of money needs to be introduced to invest in the development of new technologies and new products. And it is not easy that the logistics finance risk supervision based on the Internet of things needs to meet the requirements of all aspects. Now we carry on the feasibility analysis from the economic and technical two aspects (Hongyin Jiang, Peiqiang Li,2014).

\subsection{Technical feasibility}

The technical problem is the process that implement the Internet of things supervise logistics and financial business and realize the risk management and control the most critical issues. The Internet of things mainly depend on RFID technology, GPS technology and sensor network technology to carry out information collection. RFID is the abbreviation of Radio Frequency Identification technology. It is a widely worldwide used non-contact identification technology, it carries on the information transmission and exchange through the combination of the internet, to achieve the management of information sharing and objects intelligent and transparent (Qiang Duan, 2014). GPS can apperceive and locate moving objects. It can manage the circulation goods visually though combine with sense technology and image recognition technology. Sensor network technology is a wireless network composed of integrated and organized random distribution sensors, data processing units and communication units through self-organizing methods (Ruibo Guo, Yong Chen,2014). The sensor network technology can extract all the information of the monitored object in a comprehensive way, and is an intelligent network with the function of perceiving the real world.

The development of these technologies has been relatively mature and widely used in various industries. Therefore, it is technically feasible to apply them to the overall supervision of logistics finance, and even a single enterprise has the same strength.

\subsection{Economic feasibility}

To apply Internet of things to the risk management of logistics finance, consideration should also be given to the economic benefits of doing so in addition to solving technical problems. In recent years, China has paid great attention to the development of the Internet of things industry, Not only to give a lot of concessions in terms of policies, but also invested a lot of money and manpower to support related research development and technological innovation, and they have given strong support in all aspects, which undoubtedly created a bright future for internet of things. The construction of Internet of things requires the extensive participation of government departments and enterprises. From the social point of view, the sharing of resources and cooperation between enterprises and business realized the integrated management of resources and reduced the waste of social resources.

Combined with the above reasons, we can believe that the whole process of supervision and the risk management of logistics finance on the basis of Internet of things is economically feasible.

\section{DESIGN OF THE MODEL OF LOGISTICS FINANCE RISK MANAGEMENT BASED ON INTERNET OF THINGS}

Understanding that the Internet of things has a very positive impact on the management of logistics and financial risk, it is feasible to apply the Internet of things to the supervision and risk management of logistics finance, The model of the logistics finance risk management based on Internet of things is conceived as follows, according to the time of the risk event,the established model of logistics financial risk management is divided into three parts: before, during and after the event, they are risk identification, risk control and risk event evaluation.

In order to make the concept of modle of the logistics financial risk management has been standardized operation, improve the efficiency of risk management and establish a platform based on the model, which is named as the platform of logistics financial risk supervision. The following is a detailed description of the platform of logistics financial risk supervision (Jia Ruan,2010).

\subsection{The basic function of the platform of logistics financial risk supervision (Yan Ying, Suo Bin, 2013).}

(1) Build a network platform based on wireless data network or wired network transmission technology to realize the diversification of the Internet of things subnet, to ensure the remote monitoring and monitoring information management, storage and transmission of the linked object;

(2) By means of various network technologies, the collection points of objects in different regions are integrated into a network, At the same time, the object monitoring service is provided for the users in different regions. Information sharing is achieved by applying multiple patterns.

(3) Establish a highly compatible and highly centralized service system about Internet of things, Through the integration of various information technology, the integration of monitoring information and alarm resources is realized, and the information needed by users is collected, processed, stored and transmitted in real time (David Biederman,2010).

(4) The platform not only needs to realize the interconnection and exchange of information among heterogeneous devices, but also need to solve all kinds of problems among subsystems, such as: a large number of data transmission security, real-time exchange, network integration, business monitoring etc(Albert R. Koch1948).

Generally speaking, the logistics financial risk supervision platform should have the characteristics of precise positioning, quick response, centralized management, early warning, unity, good expansion and 
service unicom. The visual display the comprehensive function of risk supervision platform of logistics finance.

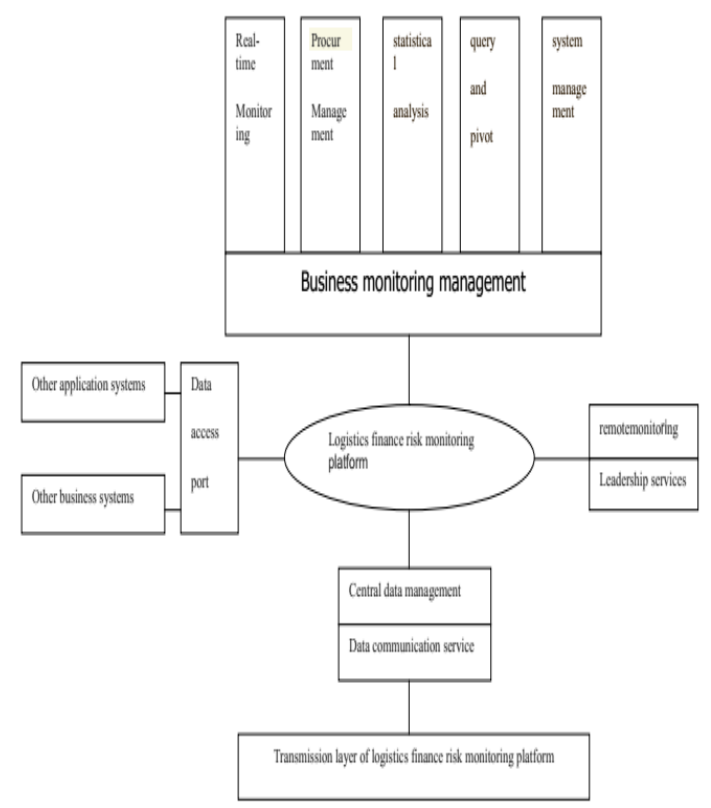

Fig 2. Conception of risk management model of logistics finance

\subsection{Structure of the platform of logistics financial risk} supervision.

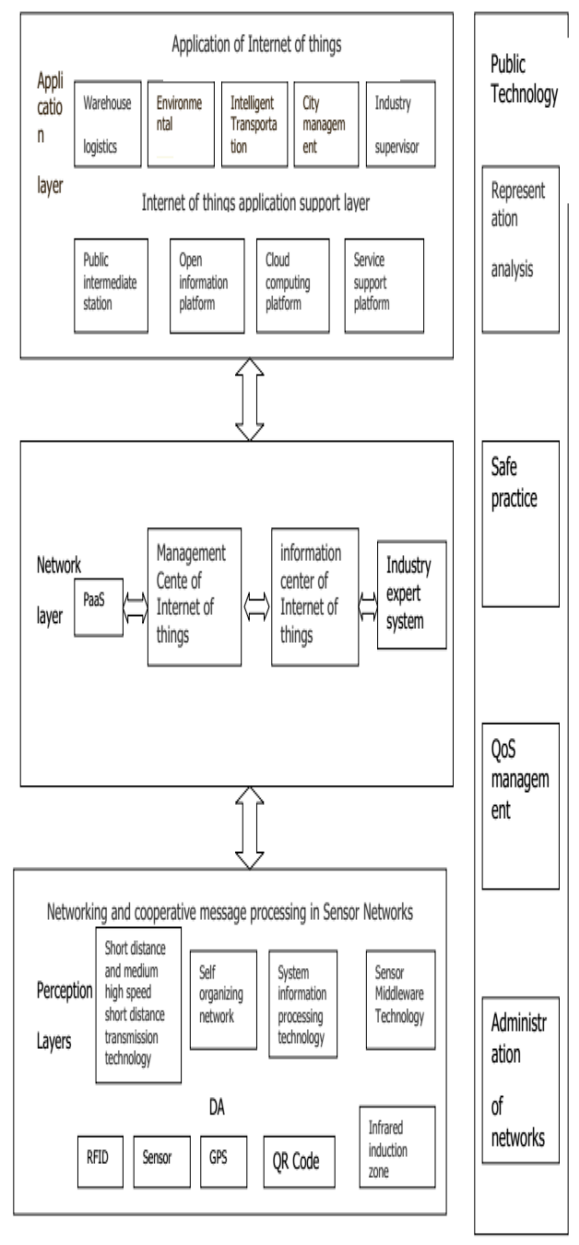

Fig 3. The structure of hierarchical graph platform of logistics finance risk supervision
On the platform of logistics financial risk supervision, we need to connected with each other among many objects. According to the current situation and actual needs, the structure of the platform of logistics financial risk supervision includes three levels: perceptionlayer of the Internet of things, network layer of the Internet of things, application layer of the Internet of things, these three levels respectively take the responsibility of access, transfer, service. By means of communication network and special equipment, the interface is clear and the structure is clear. The design takes full account of the independence of the various levels, At the same time, it is guaranteed that the maintenance of the whole system will be changed without changing the level of the system. The specific structure hierarchy is shown below ( YangLei,ZhangYizhen,2010).

\subsection{The overall structure of the platform of logistics financial risk supervision.}

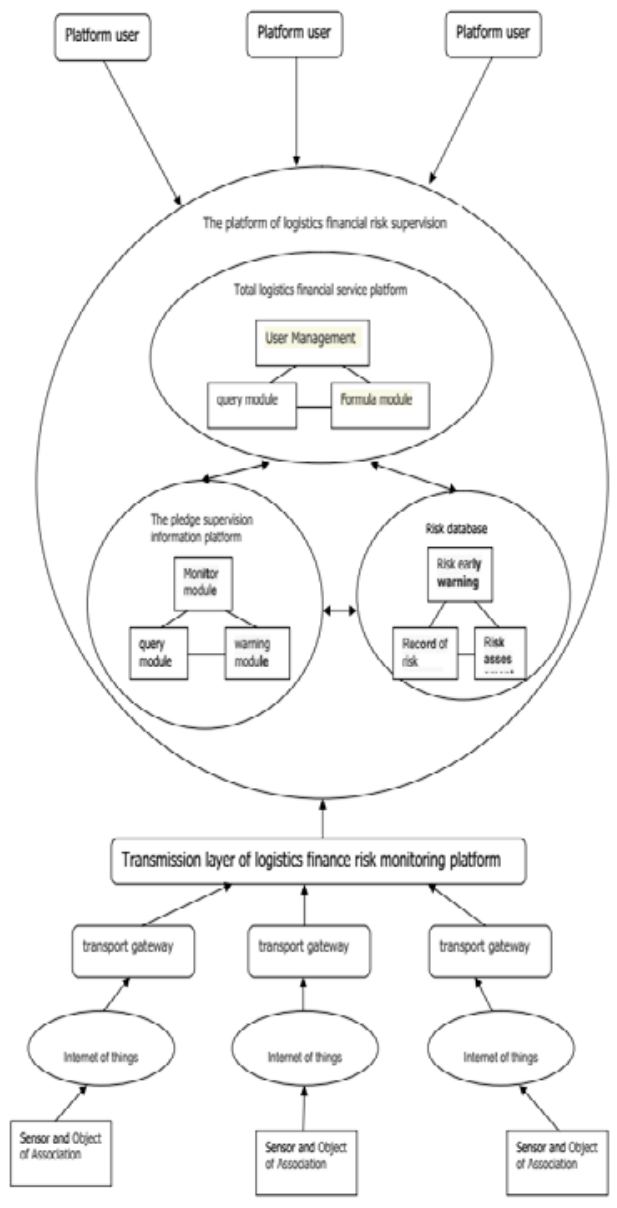

Fig 4. Structure of logistics finance risk supervision platform

In order to realize the Internet of things, the monitoring of the whole process of logistics finance risk is carried out, the risk monitoring platform is a platform of hierarchical structure of the Internet of things service, and make full use of wireless data communication technology and related professional equipment, establishing a mobile and sensitive network connecting the application center and the object of Association., obtain and transmit industry monitoring data flexibly and timely Junlong Jia, Jie Zhou,2011). The establishment of 
the platform of logistics financial risk supervision has three parts, they are logistics finance information service platform, pledge information supervision platform and risk database. The three parts communicate with each other and carry out the information transmission and feedback in a timely manner, so that the risk of logistics finance can be effectively managed and controlled. The following is the overall structure of the platform of logistics financial risk supervision.

\section{CASE ANALYSIS}

Zhongchu development stock co. ltd is a modern large-scale integrated logistics enterprises, and it's size of the financing in 2006 exceeded 6 billion. It is mainly engaged in warehousing, transportation, international forwarding, production, processing and other logistics business. Since 2003, it has initiated the supervision of pledge financing. The existing pledge supervision business related personnel more than 90 people(Yingcheng Liao, Xiaonan Liao,2010).

\subsection{The problems of the supervision of zhongchu company}

Qingdao branch of Zhongchu company uses a more standardized regulatory process, and has formed a large-scale regulatory business. However, there are still deficiencies in the whole supervision system, and these problems will gradually emerge with the continuous expansion of the enterprise logistics business and the enlargement of the scale. The main problems are as follows.

(1) The process of business supervision is complex. Not only need to make regular inventory and spot checks on stock goods, but also to fill in and issue a large amount of documents during the business process, and require the relevant personnel to sign. In this mode, enterprises need a lot of staff for information collection and transmission work, the traditional supervision process not only low efficiency, high error rate, information transmission and feedback speed is slow, and it will seriously consume the manpower, financial and material resources (Yanfei Xiao, Wenbin Zhong, 2012).

(2) The variety of the goods is complicated. For large enterprises, the wide range of customers provided a wide range of logistics and financial services, and therefore involves a variety of pledged goods is very complex, which will undoubtedly increase the difficulty of supervision. If each item is classified, inventory, and supervised, the cost will be greatly improved.

(3) The management of staff is difficult. In the existing regulatory model, it need a large number of staff to carry out business. However, the quality of staff is uneven, and once the management is weak, it is likely to bring operational risks to the company due to regulatory errors. In addition, internal staff moral hazard is also a problem, so the management of personnel is also an important aspect to consider.

(4) Lack of business process specification. The company's business processes are standardized, but because the process is complex and involved many staff, good design of business processes is difficult to accurately implement, so it is difficult to achieve the expected results (David Biederman, 2010).

\subsection{Application the platform of logistics finance risk supervision to improve}

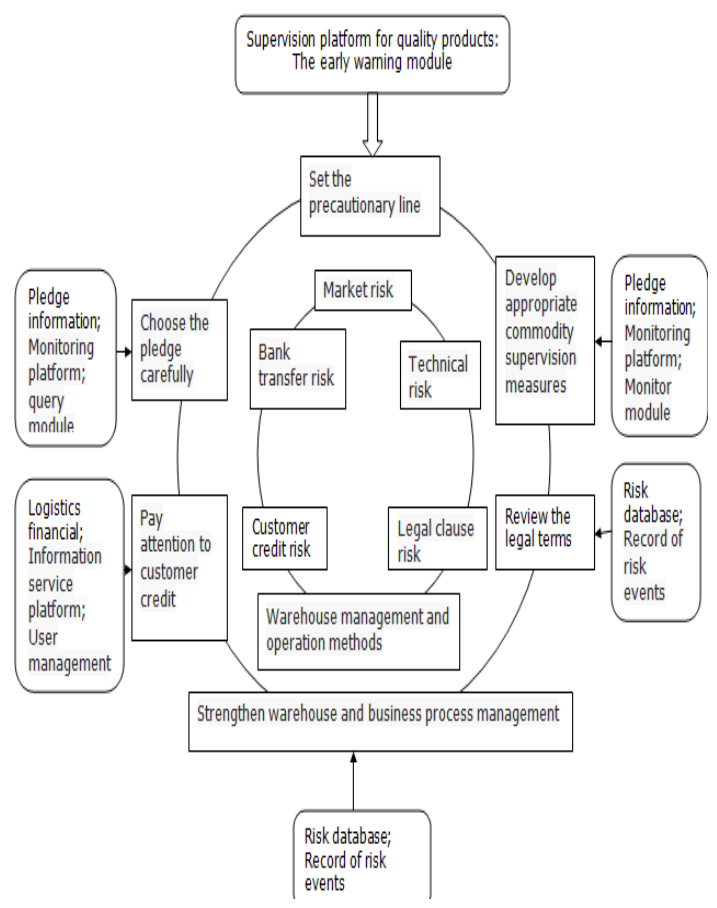

Fig 5.Qingdao branch of logistics and financial risk management improvement diagram

According to the company's case,it can be summed up: logistics finance business as well as participants will inevitably face many risks, the traditional risk control measures have been unable to meet the rapid development of logistics finance. To build a platform of logistics financial risk supervision by means of network information technology, can realize the agility of information transmission and feedback, and real-time monitoring of the goods of the goods, monitor the whole process of the operation process to reduce operational risk, the platform has perfect database, support user information to reduce customer credit risk. With the help of Internet of things, it can greatly reduce the operating cost while avoiding the risk of logistics finance, and realize the automatic management. Although based on the IOT platform risk supervision of logistics financial capital and technology early investment is large, but it has promoted the role of logistics finance industry, create economic benefits is very large, the government and logistics industry should vigorously support the logistics finance risk management model.

\section{CONCLUSIONS}

The main idea of this paper is to find out the problems existing in the current logistics financial risk management, analysis the impact of Internet of things information service technology on logistics finance risk management and study the logistics financial risk prevention measures based on the Internet of things 
information services. Establish the logistics financial risk management model based on the Internet of things information technology.

\section{REFERENCES}

[1] Albert R. Koch, J,1948. Economic Aspects of Inventory and Rece ivable Financing. Law and Contemporary Problem, 13(4): 566-578.

[2] David Biederman, J, 2004.Logistics Financiers.,The Journal of Commerce.(4): 40-42.

[3] Qiang Duan, J,2014. On the control measures of logistics financial risk in China, Tokyo literature.

[4] Ruibo Guo, Yong Chen, J, 2014.Study on the mode of networking applications in financial services, Experimental technology and management.

[5] Junlong Jia,Jie Zhou,J,2011.The risk analysis of financing logistics based on system dynamics[J].Journal of Qingdao ocean seamen.

[6] Zhili Jia, J, 2012.Analysis of logistics financial risk management, China's scientific and technological wealth.

[7] Hongyin Jiang, Peiqiang Li, J,2014. Internet of things finance and its application in the development of modern logistics. Business Times.

[8] Juan Li. Logistics Finance: a new way to solve the financing problem of small and medium sized enterprises, Shopping mall modernization.2007

[9] Yinlun Liu, Wangyang Han.J, 2015.Logistics finance risk management based on Internet of things information platform, China Logistics \& purchasing.

[10] Yingcheng Liao, Xiaonan Liao, J, 2010.The application of interactive intelligent electronic label on Internet of things, Information technology and standardization (8).

[11] Jia Ruan, J,2010Logistics financial risk and control. Logistics technology.

[12] Yanfei Xiao, Wenbin Zhong, J, 2012.Thoughts on optimizing the supply chain financial services in the Internet of things. Business Times.

[13] Lei Yang, Yizhen Zhang. J, 2010.Construction of financial risk management system of agricultural products logistics based on factor analysis. Guangdong Agricultural Sciences.

[14] Yan Ying, Suo Bin. J, 2013Risks Analysis of Logistics Financial Business Based on Evidential Bayesian Network. Mathematical Problems in Engineering.

[15] Junjing Yuan, TangQi, 2014. Logistics financial risk analysis. Journal of southeast university. 